DOI: https://doi.org/10.34069/AI/2021.46.10.25

How to Cite:

Kundi, G.M. (2021). Relationship between Emotional Intelligence and Managerial Decision-Making Styles: Multi-Mediation Analysis. Amazonia Investiga, 10(46), 244-258. https://doi.org/10.34069/AI/2021.46.10.25

\title{
Relationship between Emotional Intelligence and Managerial Decision-Making Styles: Multi-Mediation Analysis
}

\author{
العلاقة بين الأكاء العاطفي وأنماط اتخاذ القرار الإداري: تعليل متعدد الوساطة
}

Received: August 10, 2021

Accepted: Octobe 28, 2021

Written by:

Ghulam Muhammad Kundi

https://orcid.org/0000-0003-3082-1611

\begin{abstract}
Every individual makes decisions with a different mindset. Emotional-Intelligence is key for every leader working in the prevalent work settings in the era of technological revolution. Experts have categorized impact of emotional intelligence (EI) into Personal intelligence (PEI) and Social intelligence (SEI). The theoretical model of decision-making styles (DMS) includes the 'People-oriented' and 'Task-oriented' decision making styles (PDMS \& TDMS). This study has investigated the comprehensively established models of relations between EI and DMS. The main research question was 'How managers' DMS is influenced by their PEI and SEI?' The literature review was conducted by employing the thematic analysis. The cross-sectional survey approach was employed to collect data. The study investigated the emotional capacity of decision-makers at workplace which characterized by flooding of information, insecurity, and wider digital interactions - which result in the high levels of stress. This study is a spadework to further explore the same issue with different settings and data sources.
\end{abstract}

Key Words: Emotional Intelligence, Personal and Social Intelligence, Managerial Decision-Making Styles, People-oriented and Task-oriented decision-making styles.

يتخذ كل فرد قرار اته بعقلية مختلفة. أصبح الذكاء العاطفي لا غنى عنه لكل مدير يعمل في ظل البيئة الحالية للتورة التكنولوجية. تكنولوجيا

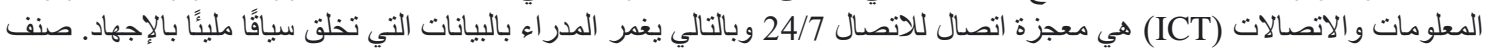

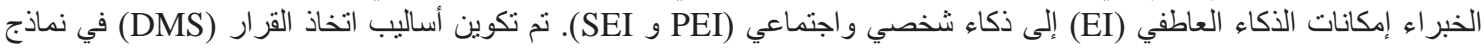

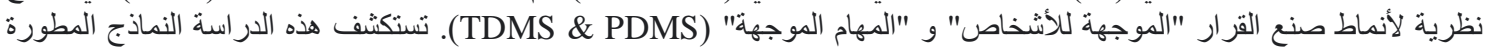
عالميًا للعلاقات بين DI و DIS. السؤ ال البحثي الرئيسي في الدراسة هو "كيف يتأثر نظام إدارة الوجهات السياحية (DMS)

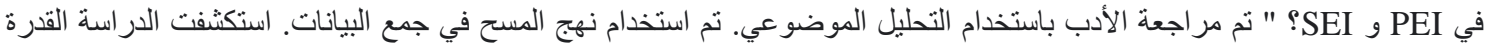

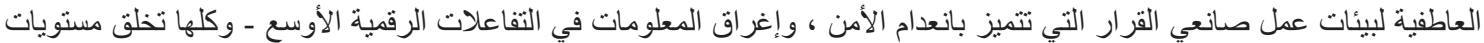
عالية من الإجهاد المهني. ستعمل هذه الدر اسة بمثابة عمل متقطع في استكثاف المشكلة نفسها من نفس مصادر البناف الييانات في إعدادات مختلفة. الكلمات الرئيسية: الذكاء العاطفي ، والذكاء الثخصي و الاجتماعي ، وأساليب صنع القرار الإدارية ، وأساليب صنع القرار الموجهة للأفراد و الموجهة نحو المهام.

\section{Introduction}

For a manager, decision-making is a hard and challenging task, and it is considered a tension-based activity. All managers in their respective organizations are always compulsorily doing the business of information and decision making (Gatseliuk, Strelbitska, Herasymchuk, Pavlyshyn, \& Khrystiuk, 2021). The managers make these decisions either in the environment of certainty or uncertainty, in case of uncertainty, they producing risky decisions, the result from working under stressful enjoinment and conditions. Yet for effective decision making one needs multiple skills to deals with the diversity of the situations (Mayer \&

Department of Health Administration, College of Public Health and Health Informatics, Al-Bukayriyah Qassim University, Kingdom of Saudi Arabia. 
Salovey, 1997). Here comes the role of emotional intelligence, which is considered one the critical skills for a manager to be successful in the contemporary insecure and ever-changing environment of the work (Sarkhosh \& Rezaee, 2014). It depends on the ability of a decision-maker to first comprehend his own emotions and his colleague or subordinates so he might be able to identify the impacts of emotional disturbance on the behaviors of employees (Hacioglua \& Yarbayb, 2014). Luthans, \& Youssef (2007) states that emotional intelligence is the awareness of a person about his own emotions and feelings while working in an organization dealing with other people since human behavior is ever-changing. It is one of the main capabilities that fundamentally pave the way to build self-control. Intelligence has two categories 1. Practical intelligence or social intelligence which often overlooked and remains unfulfilled (Rahmana, Uddina, \& Rahman, 2016). People with emotional intelligence could manage emotions for self-motivation, accomplish their assignments, and conduct interpersonal emotional management that helps them in successfully managing and taking care of the interrelationships with fellow workers (Goleman, 1998). Emotional intelligence can complement the academic intelligence that is a cognitive process and competence measured through an intelligence quotient (Hacioglua \& Yarbayb, 2014). Gardner \& Qualter (2010) assert that emotional intelligence skills are a decisive factor for the performance of the employees, and it predicts an individual's leadership behavior. It is observed that a leader with good emotional intelligence could achieve a high level of group effectiveness, Luthans, \& Youssef-Morgan (2017) also recorded similar observations.

Emotional intelligence predicts the effectiveness of an organization in multiple fields, for example, recruitment and retention, talent growth and development, commitment, teamwork, morale, innovation, and service quality (Rahmana et al., 2016). According to Mullakanda \& Dissanayake (2015), emotional intelligence has four categories i.e., the accuracy of emotion's perception, usage of emotions for assistance in thinking, understanding the emotions, and the emotions-management. Salovey \& Mayer hypothesized emotional intelligence as the process to appraise, express, and regulate emotions by the person himself and that of others. The managers use emotions through a flexible and creative mechanism for planning and thinking. It is generally accepted that EI is an essential element of today's learning organizations (Sarkhosh $\&$ Rezaee, 2014), and it consists of fixed skills that are the prerequisite for effective people's interaction and performance, these skills include the recognition and regulation of emotions, self-control, setting the goals, accepting the social responsibility, empathy, problem understanding and resolving, conflict management, inter alia the skills required for leadership and group participation (Bavolar \& Orosova, 2015). Hacioglua \& Yarbayb (2014) are of the view that it is helpful to leaders in developing effective interpersonal relations for superior performance Gardner \& Qualter (2010.

Everybody makes decisions including the managers in a public or private organization Mullakanda \& Dissanayake, 2015). It is a scholarly activity that is based on a systematic behavior, however, according to the general approach of Simon 'intelligence-design-choice' which is used by almost all managers under the environment of certainty, uncertainty, and risky decision environments. Yet, in such situations, innovative and creative decision-making is always required and appreciated. Managers might have different decisionmaking styles that differ from the public and private sector but their work settings need them to be flexible and adapt to different decision-making styles keeping in view the circumstances and conditions (Rahmana et al., 2016). Current and cut-throat competition demands dynamic and growing survival of today's organization is dependent upon appropriate, timely, and effective decisions taken by leaders who perform intellectually and wisely (Sarkhosh \& Rezaee, 2014) since decision making is an instrumental element of organizational behavior, therefore, decision-making styles of a manager and decisions made by him largely affects his/ her perceptions (Luthans et al., 2010).

The decision-making styles of organizational leaders are dependent on numerous factors, especially on their emotional intelligence skills. This study is an effort to explore the impact of EI in defining the decisionmaking styles of managers.

\section{Research Questions}

1. Is there any significant association between PEI, SEI, PDMS, and TDMS?

2. To what extent does PEI and SEI predict the PDMS and TDMS.

3. To what extent PEI mediates the relationship between SEI and PDMS, SEI, and TDMS?

4. To what extent do the demographic responses vary? 
Proposed Hypotheses

$\mathrm{H}_{1}$. There is a significant association between SEI, PEI, and PDMS.

$\mathrm{H}_{2}$. TDMS is significantly correlated with SEI and PEI.

$\mathrm{H}_{3}$. PDMS is a significant predictor of SEI and PEI.

$\mathrm{H}_{4}$. SEI and PEI significantly define variance in the TDMS.

$\mathrm{H}_{5}$. PEI plays a greater significant role as compared to SEI in predicting the PDMS.

$\mathrm{H}_{6}$. PEI significantly mediates the relationship between SEI and the TDMS.

Demographic Impacts

$\mathrm{H}_{7}$. The private sector is scoring greater than the public sector.

$\mathrm{H}_{8}$. The health sector is scoring greater than the education sector.

$\mathrm{H}_{9}$. Females are scoring less than males.

$\mathrm{H}_{10}$. Senior respondents are scoring more than the juniors.

$\mathrm{H}_{11}$. Less experience are scoring higher than the more experienced counterparts.

\section{Literature review}

Emotional intelligence is considered as one of the popular research areas among the research community, which is an individual's ability to comprehend his own emotions as well as of his fellow workers to comprehend and guide their thinking and decision making (Salovy \& Mayer, 1990). Svetlana (2007) has defined it as the capacity of a person to consolidate the personal and colleagues' feelings in the organizational set up not only to motivate himself and others as required by the organization they are serving. Thus, it is connected with numerous psychological skills that also play a greater role to influence an employee how to cope with the increasing workloads and pressures (Mullakanda \& Dissanayake, 2015). Emotions are considered tools that help managers to organize themselves and the things that could lead to greater human performance (Svetlana, 2007). Social intelligence is one of the abilities of an individual to understand the emotional states of an individual and group behaviors and then react in an emotionally stable behavior for the success of the individual and group performance (Sarkhosh \& Rezaee, 2014). According to Gardner (1983), emotional intelligence has numerous constructs like, intrapersonal and that of interpersonal intelligence labeled as personal intelligence conceived from the concept of social intelligence. Rahmana et al. (2016) developed the concept of emotional intelligence, they combined social intelligence and constructive thinking, further categorized into perceiving and expressing emotions, facilitate thinking, comprehending emotions, and the management of motions.

Conventionally, researchers have emphasized the adaptive nature of cognition. But recently they are focusing more on broader approaches to understand intelligence (Schutte et al., 1998). The ability of a manager to control the emotions is significant for an organization since the high level of emotional intelligence helps the leadership in developing and maintaining peace in oneself inter alia they could effectively and confidently cope with issues and challenges during work while interacting with colleagues and subordinates (Svetlana, 2007; Sarkhosh \& Rezaee, 2014). Salovey \& Mayer (1990) were the pioneers who used 'emotional intelligence as a unique construct and reported that it consists of an appraisal and expression of the emotion, which is appraisal and expression of emotion in oneself and other fellows, they categorized it into verbal and nonverbal, nonverbal expressions and empathy. The second category is regulating emotions which is related to the regulation of one's own emotions and organizational participants, the third category is the use of emotions for problem-solving, which focuses on flexible planning, creative thinking, and redirected attention and motivation. (Svetlana (2007) also shared similar results consistent with the previous study of Schutte et al. (1998).

Mayer \& Salovey (1997) have given a list of seven components including self-awareness, emotion preservation, persuading, firmness and motivation, farsightedness and integrity, and the last is interpersonal sensitivity. It is believed by the researchers that training management is important for emotional intelligence and stability, according to Luthans et al. (2010) and Sarkhosh \& Rezaee (2014), the emotional intelligence of employees could be sequentially increased starting from self-awareness of emotions and that of the fellow workers. And once they develop self-understanding, they move ahead to comprehend other individuals and groups in the organization, this could be helpful to understand and develop positive behavior desired in the work setup. 


\section{Magnitudes of Emotional Intelligence}

Howard Gardner (1983) has introduced intrapersonal and interpersonal intelligence. Intrapersonal intelligence refers to the ability of an individual to control oneself by developing a personal understanding and feelings, the needs, desires, and goals. These abilities can help him motivates himself (Holt, 2007). Similarly, interpersonal intelligence is related to emotional sensitivity and group psychological conditions. It is believed that emotional intelligence defines an individual's capacity to develop skills and competencies related to personal intelligence and social-emotional intelligence given by Goleman (1998):

\section{Personal Emotional Intelligence}

1. Self-awareness refers to emotional awareness, elevated self-esteem, and the ability to accurate selfassessment.

2. Self-regulation implies the ability of an individual to control his emotion and impulse, flexible managing change, and the ability to be creative and innovate.

3. Motivation means the need to achieve, the need to initiate, and finally the optimism.

\section{Social-Emotional Intelligence}

1. Empathy, which is the understanding of others, and a willingness to fulfill the needs of others, the ability to 'change in the individual's and or group's emotional state, and

2. Social skills stand for persuasion, managing the conflict, and leadership skills. (Cadman \& Brewer, 2001).

These factors influence the perceptions and responses of each individual i.e., empathy and motivation which affect the perception of events and develop response accordingly (Schutte et al., 1998). Recent research by Hacioglua, \&Yarbayb (2014) was founded on Gardner (1983), though he used intrapersonal and interpersonal intelligence instead of emotional intelligence.

\section{a. Personal Dimensions of Emotional Intelligence}

\section{i. Self-Awareness}

Self-awareness refers to knowing one's emotions i.e., inner conditions, priorities, capacity, and intuitions for understanding Goleman (1998). Researchers stress the dispositional qualities of self-awareness i.e., aims-in-life (Hacioglua \&Yarbayb (2014) it is connected to remain aware of one's emotions, impulses, and moods (Rahmana et al., 2016).

\section{ii. Self-Regulation}

It involved taking care of one's inner conditions, instincts, and abilities, including self-control, conscientiousness, malleability, honesty, and novelty besides self-assessment to adjust his behavior to external demands. One's with weak self-regulation is likely to be impolite as compared to those with high self-control (Zimmerman \& Schunk, 2011). The skills prerequisite for self-regulation has been researched under the rubric of self-regulated learning by Zimmerman \& Schunk (2011). They reported that people with effective self-regulation set their goals, manage time, set suitable strategies, prioritize materials, use flexibly, assess their learning for their productivity, and do the right tunings (Baczynska, 2015). EI is a tool that helps in selecting the right strategy that best facilitates people's interaction, i.e., support to fellows, and forgoes strategies with no or even a negative impact on these interactions i.e. avoidance (Gardner \& Qualter, 2010).

\section{iii. Motivation}

Motivation is guiding to center on the goals despite barriers with optimism for success without fear to fail (Luthans et al., 2010), similarly, self-motivation is based on the expectancy-value of motivation (Rahim \& Malik, 2010). It has elements like hope, values, and effectiveness. Expectation refers to confidence in doing a job (Hacioglua \&Yarbayb, 2014). From a cognition viewpoint, it is imperative to consider emotion and motivation. The concept of motivation is explored in several fields regarding what and why the behavior 
of the employees (Baczynska, 2015). The literature reports that there is significant relationships between motivation and performance (Kang, 2015).

\section{b. Social Dimensions of EI}

\section{i. The Empathy}

Empathy refers to recognize the feelings of others or it refers to the talent to share ones emotional experiences without involvement (Kang, 2015), so empathy implies recognizing the feelings, concerns, and needs of others, one of the critical skills, instrumental for emotional intelligence (Rahmana et al., 2016). People with high empathy have an accurate understanding of others. They are less likely to exhibit anger and aggressiveness (Mayer et al., 2008a). It is the swing from a 'self-interest' mindset to the 'commoninterest i.e., emotions (Rahim \& Malik, 2010). The right application of empathy increases the respect and trust of employees in managers ((Bar-On, 2006).

\section{ii. The Social Skills}

The ability of an individual to cope with social relationships (Salovey \& Mayor, 1990), which consists of tactics of communicating with others, conflict resolution, change management leadership, relationship management, collaboration and cooperation, and team working (Baczynska, 2015)). It is related to the ability to manage problems without blaming fellow workers preventing the negative feelings to impede collaboration (Rahmana et al., 2016). Employees with good social skills avoid aggression, while a person with weak social skills exhibits bad and antisocial behavior (Mayer et al, 2008b). A person with powerful social skills prepares well to improve social relations using management tactics to tackle the stress-ridden work settings (Sarkhosh \& Rezaee, 2014).

\section{Decision-Making Styles}

Decision-making is a scientific process based on scientific facts and figures, the process includes intelligence, design, and choice of the best alternative, however the most important is the decision-making style of the decision-maker which manifests his mindset and approach (Sims, Faraj, \& Yun, 2009). During this process, decision-maker use facts and figure, conceptualize and envision the future of his organization to who he is responsible. Hence, familiarity with a manager's decision-making style is helpful to decide how he is going to respond in numerous work settings (Del Missier, Mantyla, \& Bruine de Bruin, 2010; Bavolar \& Orosova, 2015). The decision-making process is dependent on several factors, i.e., the decisionmaker, background, decision-making style, the value system, and the manipulating power (Sims et al., 2009). Fundamentally, decision-making is a menta process, which is rooted in the psycho-intellectual ability of an individual perception, action, and closure. The mental style is used to link these practices and axing the event even in the milieu of vagueness (Del Missier et al, 2010). Normative model of decision making submits generally need decision making skills i.e., (a) identify the potential choices, (b) sensing the anticipated results from each choice, (c) measuring the impact of each result, (d) assessing the individual possible outcome, and (e) selecting the best choice consistent to needs of an organization (Luthans et al., 2010). Kang (2015) defined the decision-making style that 1) how a person thinks of the problem, 2) then communicates with fellows, and 3) how he anticipates fellows to behave and perform. There are decisive, flexible, hierarchic, and integrative styles. In a decisive style, minimum information is used for the sharp solution. In a flexible style, mostly contingent and adaptive while, hierarchic, tries to protect the relationships and trust and finally, the integrative prefer to be creative but multiple models to resolve issues with trust and teamwork (Bavolar \& Orosova, 2015). Rowe \& Boulgarides (1983) gave a decision styles model that accepts the influence of values and perceptions. Figure 1 is picturesque of the same which recommends that decision-makers are driven by four factors. These styles are analytic, directive, conceptual, and behaviorally consistent with needs behavior which is motivated by achievement, power, and affiliation motives. 


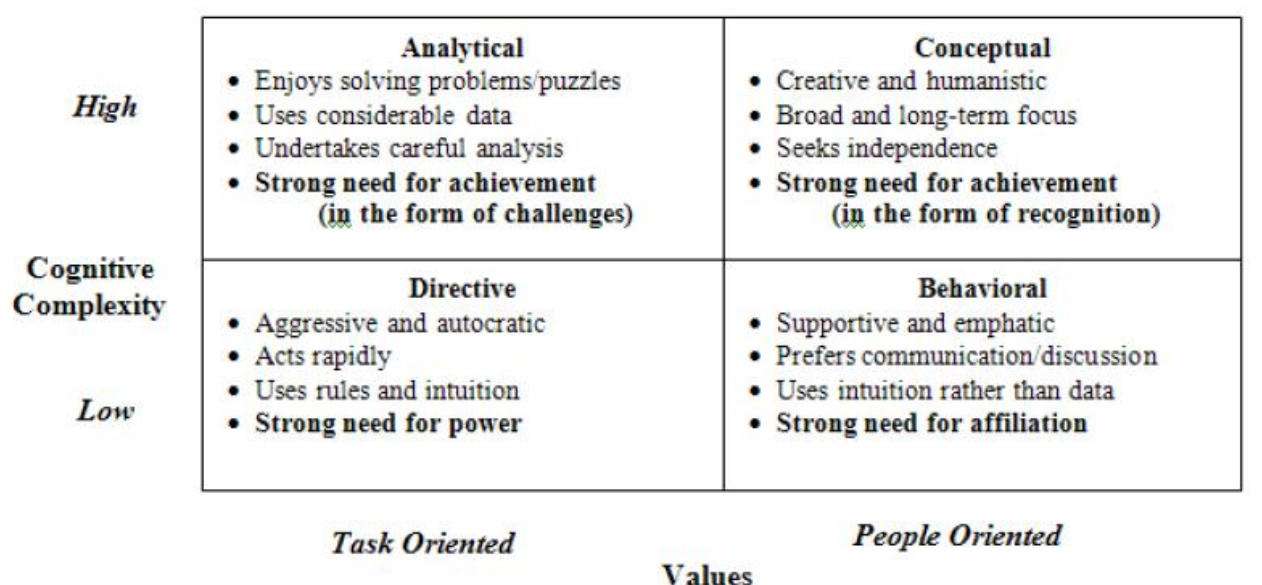

Figure 1. Decision-Making Styles (Rowe \& Boulgarides, 1983)

Source: Rowe \& Boulgarides (1983)

\section{a. Task-Oriented Decision Making}

i. Analytical

This model states that managers with analytical capability are task orientation. They exhibit a high level of patience for ambiguity. They consider several alternate choices and collect data from every possible source before decision-making. They are careful to take enough time, but their response is effective even in an uncertain environment. They are rational and eager to achieve through novel challenges. They have cognitive complexity but like to collect and analyze data (Del Missier et al, 2010). However, the main disadvantage of this style includes delayed decisions, issues with teams, and inflexibility. Despite these, however, it has several strengths since dependence on facts and data, one can reduce the chances of a wrong decision.

\section{ii. Directive}

In this style, decision-makers have little tolerance for ambiguity, and mostly task related (Sims et al., 2009), have faith in action and results, hang on the facts, use rules, regulations, and follow a scientific model for problem-solving. They make sharp decisions and have non democratic management style. Rowe \& Boulgarides states that these managers are driven by power because they are results-oriented, therefore, they try to be dominant on fellow workers and have low patience for haziness, dislike cognitive intricacy, thus, less dependent on data thereby uses the least alternatives of choice for decision making.

\section{b. People-Oriented Decision Making}

\section{i. Behavioral}

These are driven by affiliation need, have low cognitive density but strong people's orientation, communicate with no trouble, and are human-centric. They welcome suggestions, set to conciliation, and exercise lassies fair. This style is the most humanistic. They use instinct and feelings to resolve issues. Managers in a group incline to solve problems through the application of feeling and instinct, and they avoid conflict (Del Missier et al, 2010).

\section{iii. Conceptual}

These are also result-oriented like an analytical manager, yet prefer extrinsic rewards i.e., praise, recognition, and independence. They don't bother with the cognitive complexities of the environment inter alia they have a strong orientation for the people (Del Missier et al, 2010). They have a creative and innovative attitude, collect facts and figures from multiple sources, elaborate on different choices. They explore all possible solutions before final a decision (Bavolar \& Orosova, 2015). Conceptual decisionmakers are action-oriented but they focus more on the social aspects of work settings (Luthans et al., 2010). 


\section{Demographic Impacts}

Demographic influences on the EI of managers are frequently recognized in analyzing the EI behavior. The existing study reveals that demographic differences have significant impacts and thus change the response of sample individuals accordingly. This study has used t-test to check the significant mean difference of various groups of the samples.

\section{Theoretical framework}

Figure 2 represents the theoretical framework of this study. This schematic diagram has been used as a research guide. The model exhibits the variables for which data were collected through a field survey using a structured questionnaire. Likewise, it also explains the relationships between them as suggested by the literature, based on which the hypotheses have been constructed and tested.

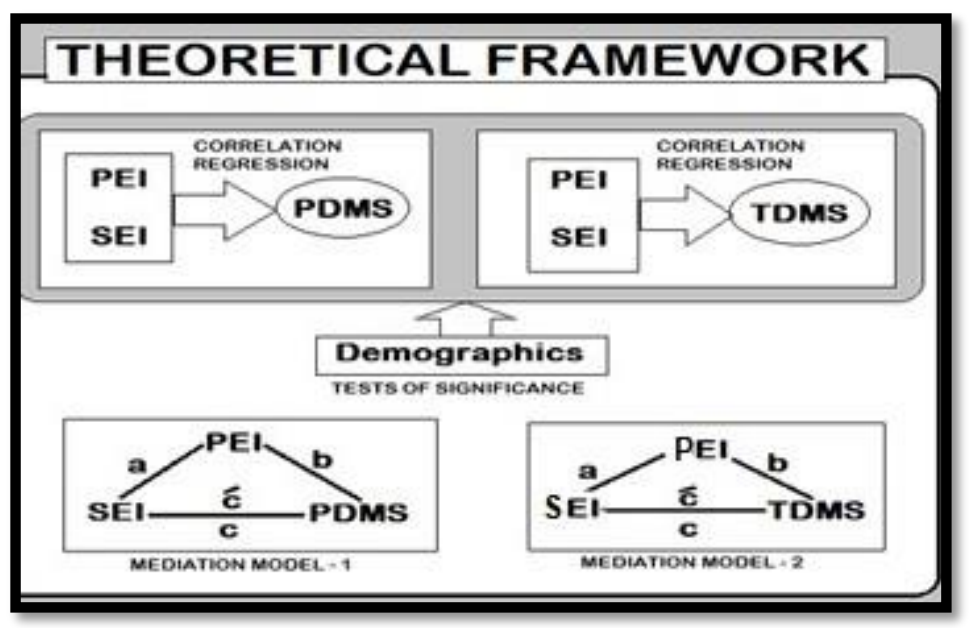

Figure 2. Schematic Diagram of the Theoretical Framework.

The model describes different research questions in respect among the relationships between the independent, dependent, mediating, and demographic' variables for 'test variables' i.e., decision-making styles 'PDMS and TDMS'. It also explain the logical design to test the mediation for Personal EI between the SEI relations to the PDMS and TDMS. This model helps develop a 'Scientific View' of the problem under study as well operates as the modus-operandi to collect and analyze data to answer the research questions.

\section{Research methodology}

This study used a survey approach. The population of the study was managers working in public and private health and education sectors. Data was gathered through a pilot study to determine the sample size $(n=32)$. The emerging sample size is $(n=151) .160$ questionnaires were distributed. Primary data was collected through cross sectional survey. A 7-point scale instrument was extracted from the previous studies and was administered to collect the responses from the selected samples. The instruments contained questions for the independent, dependent, mediating, and demographic variables used in the study. The return rate was $93 \%$.

Table 1.

Data from Pilot Study used for Sample Size.

\begin{tabular}{ccccc}
\hline $\mathrm{n}=$ & {$\left[\left(\mathrm{sd}^{2}\right) /\left(\left(\mathrm{z}^{2} / \mathrm{e}^{2}\right)+\left(\mathrm{sd}^{2} / \mathrm{N}\right)\right)\right.$} & & $\mathrm{N}$ \\
\hline $\mathrm{z}-$ Value & $\mathrm{SD}$ & $\mathrm{E}$ & $\mathrm{N}$ & $\mathrm{n}$ \\
1.96 & 0.056 & 0.007 & 390 & 150.8 \\
\hline
\end{tabular}

\section{Tools for Data Analysis}

Attride-Stirling (2001) Thematic network analysis; Glasser \& Strauss's (1967) 'Grounded-theory' Ritchie \& Spencer's (1994) 'Framework-Analysis' and Toulmin's (2003) 'argumentation theory are the structured 
methods used to analyze the secondary sources of data with regards to the qualitative enquiry method. The TFA uses theory as a model for collecting and organizing the facts and figures. The TNA theory is based on a well-established model to perform such functions in the field of social research (Goode \& Hatt, 1952: 9; Babbie, 1993:49; Sekaran, 1999: 103). Based on the above, a literature review was done through thematic network analysis. Correlation and regression were used in SPSS to calculate the power, existence, and direction of the 'relationship' among the research constructs, and the influence of the predictors on the criterion. Mediation analysis was conducted using Baron \& Kenny (1986) to determine the critical role of mediators. To compute the group mean differences, a t-Test was used.

\section{Results and discussion}

\section{Descriptive Results}

Table 2.

Qualification/Designation Cross-tabulation.

\begin{tabular}{llll}
\hline & & Designation \\
\hline & & $18-19$ & $20-21$ \\
Qualification & Masters & 11 & 01 \\
& MPhil & 46 & 12 \\
Total & PhD & 24 & 28 \\
\hline
\end{tabular}

Table 3.

Gender-Qualification Cross-tabulation.

\begin{tabular}{lllll}
\hline & & Qualification & \\
\hline & & Masters & MPhil & $\mathrm{PhD}$ \\
Gender & Male & 11 & 31 & 38 \\
\multirow{2}{*}{ Total } & Female & 7 & 27 & 18 \\
\hline
\end{tabular}

Table 4.

Sector: Health -Education Cross-Tabulation.

\begin{tabular}{llll}
\hline & Sectors & \\
\hline & & Health & Education \\
Sector & Public & 16 & 49 \\
\multirow{2}{*}{ Total } & Private & 08 & 55 \\
& & 24 & 104 \\
\hline
\end{tabular}

Table 5.

Descriptive Statistics.

\begin{tabular}{llllll}
\hline & $\mathrm{n}$ & Min. & Max. & Mean & Std. Deviation \\
\hline PEI & 128 & 1 & 5 & 4.92 & .361 \\
SEI & 128 & 1 & 5 & 4.73 & .427 \\
TDMS & 128 & 1 & 5 & 4.85 & .354 \\
PDMS & 128 & 1 & 5 & 4.78 & .387 \\
\hline
\end{tabular}

\section{Testing of Hypotheses}

The results of the hypotheses have been elaborated in this section. Six hypotheses were proposed to investigate the relationship and impact and five hypotheses were proposed to test the significant groupmean differences. 


\section{Testing for Association}

Hypothesis-1: Predictors are significantly correlated with the Criterion variable.

Table 6.

Correlations $(n=128)$

\begin{tabular}{lllll}
\hline & & PEI & SEI & TDMS \\
\hline Personal Emotional Intelligence PEI & $\mathrm{r}$ & 1 & & \\
Social Emotional Intelligence - SEI & $\mathrm{r}$ & $.259^{* *}$ & 1 & \\
Task-oriented Decision Making Style - TDMS & $\mathrm{r}$ & $.766^{* *}$ & $.267^{* *}$ & 1 \\
People-oriented Decision Making Style - PDMS & $\mathrm{r}$ & $.747^{* *}$ & $.406^{* *}$ & $.637^{* *}$ \\
\hline
\end{tabular}

**. Correlation is significant at the 0.01 level (2-tailed).

Table 6 presents correlation results for the connection between the PEI, \& SEI and PDMS, TDMS, \& DMS. The results show strong and significant association of PEI with all three criterion variables =i.e., PDMS r $=0.747$; and TDMS $r=0.766$. Yet, SEI has shown weak relation with all predictors in contrast to the PEI. Likewise, as a whole, the EI has a powerful and significant relationship with three dependent variables. Based on the results, therefore, our hypothesis 01 is substantiated.

\section{Cause-n-Effect Testing}

Second research question was about the prediction of decision-making styles by personal and social dimensions of emotional intelligence. Regression analysis was employed to find the answers. Hypothesis 02 examines the influence of PDMS by PEI and SEI.

\section{a. SEI and PEI as Predictors of TDMS}

Hypothesis-2 Predictors explain variation in Decision-Making-Style

Table 7.

Direct Impact (H2)

\begin{tabular}{lllllllll}
\hline Model & $\mathrm{R}$ & $\mathrm{R}^{2}$ & Adjusted $\mathrm{R}^{2}$ & $\begin{array}{l}\text { SE of } \\
\text { Estimate }\end{array}$ & $\mathrm{F}$ & Beta & $\mathrm{p}$ & Support \\
\hline 1 & $.768^{\mathrm{a}}$ & .585 & .567 & .22612 & 85.640 & .737 & .000 & Yes \\
& & & & & & .773 & .001 & Yes \\
\hline
\end{tabular}

a. Predictors: (Constant), SEI, PEI

a. Dependent Variable: TDMS

We can see in Table 9 that R2 is 0.585 , which means that about $58.5 \%$ of the variance is caused by SEI and PEI in the criterion variable. The p-values of the predictors are much below the required critical value of 0.05 , where both the predictors are significant to bringing change in the PDMS. Thus, results suggest the acceptance of 2 nd hypothesis.

\section{b. Predicting PDMS by SEI and PEI}

Hypothesis-3 IVs explain variation in the DV

Table 8.

Direct Impact (H3)

\begin{tabular}{|c|c|c|c|c|c|c|c|c|}
\hline Model & $\mathrm{R}$ & $\mathrm{R}^{2}$ & Adjusted $\mathrm{R}^{2}$ & SE of Estimate & $\mathrm{F}$ & Beta & $\mathrm{p}$ & Support \\
\hline 1 & $.782^{\mathrm{a}}$ & .598 & .590 & .24716 & 92.492 & $\begin{array}{l}.678 \\
.238\end{array}$ & $\begin{array}{l}.000 \\
.000\end{array}$ & $\begin{array}{l}\text { Yes } \\
\text { Yes }\end{array}$ \\
\hline
\end{tabular}

a. Predictors: (Constant), SEI, PEI

a. Dependent Variable: PDMS 
$\mathrm{R}^{2}$ in Table 10 is 0.59 .8 , which shows about $60 \%$ of the variance in the TDMS due to the influence of SEI and PEI, however, it is to be noted that only PEI emerged as a significant predictor at p-value $=0.000$, which brought the change in the PDMS, while SEI is significant at p-value .000 which is less than the threshold value i.e., 0.05 or $5 \%$. Similarly, Beta-value for PEI weight is 0.678 but SEI shows a Beta-value of .238. It is therefore concluded that hypothesis 03 is partially accepted as true.

\section{Mediation-Analysis}

Mediation analysis is used to get answer for research questions and to find the role of mediators in the relationship between predictors and criterion variables. It is reported that Social-Emotional Intelligence (SEI) is the first requirement for a worker to work in a team, this is why SEI is used as a predictor and Personal Emotional Intelligence (PEI) as a mediator.

\section{a. Mediation by PEI between SEI \&PDMS}

Hypothesis-4 PEI mediates the relationship between SEI- and DMS.

Computing a

Table 9.

Model Summary.

\begin{tabular}{llllllll}
\hline Model1 & $\mathrm{R}$ & $\mathrm{R}^{2}$ & Adjusted $\mathrm{R}^{2}$ & $\mathrm{~S} . \mathrm{E}$ & $\mathrm{F}$ & $\beta$ & $\mathrm{p}$ \\
\hline PEI & $.249^{\mathrm{a}}$ & .062 & .055 & .34280 & 8.344 & & 0.005 \\
& $\mathrm{SEI}$ & & & & & 0.249 & 0.005 \\
\hline
\end{tabular}

a. Predictors: (Constant), SEI

a. Dependent Variable: PEI

Regression analysis was run to investigate the effect of SEI upon PEI. The findings revealed that SEI shows $6.2 \%$ variance upon PEI, the goodness of fit i.e., $F=8.344 p<0.05$ was found significant, whereas $\beta=0.249$ explained that $24.9 \%$ change is possible in PEI due to SEI. Thus, results suggest the acceptance 04 .

Computing c, $\hat{\mathrm{c}}, \mathrm{b}$

Table 10.

Model Summary.

\begin{tabular}{lllllllll}
\hline DV & IV & $\mathrm{R}$ & $\mathrm{R}^{2}$ & $\Delta \mathrm{R}^{2}$ & $\mathrm{~F}$ & $\beta$ & $\mathrm{p}$ & Support \\
\hline PDMS & Constant & $.407^{\mathrm{a}}$ & .166 & 166 & 24.999 & & 0.000 & \\
& & SEI & & & & 0.407 & 0.000 & Yes \\
Model 2 & & & & & & & & \\
PDMS & Constant & $.772^{\mathrm{b}}$ & .597 & .431 & 92.492 & & 0.000 & \\
& SEI & & & & & .238 & 0.000 & Yes \\
& PEI & & & & & .678 & 0.000 & \\
\hline
\end{tabular}

a. Predictors: (Constant), SEI

b. Predictors: (Constant), SEI, PEI

a. Dependent Variable: PDMS

Table 10 presents the results of Hierarchical regression in which PEI was used as a mediator between SEI and PDMS. In the first model, PDMS is predicted by SEI. R2 $=0.166$, explained $16.6 \%$ variance upon PDMS by SEI, the goodness of fit $\mathrm{F}=24.999, \mathrm{p}<0.05$ while Beta $=0.407$ means one unit change in SEI could bring 40.7\% change in PDMS. Furthermore, in the second model, PEI was added as a mediator to calculate the path $\mathrm{b}$ and $\mathrm{c}$ prime. The $\mathrm{R} 2=0.597$ points to the significant impact while the change in $\mathrm{R} 2=0.431$ implies $43.1 \%$ change occurs in PDMS due to inclusion of mediator, in addition, model fitness $\mathrm{F}=92.492, \mathrm{p}<0.05$ is also found significant while a beta for SEI $=0.238$, and PEI beta $=0.678$ were also significant at $\mathrm{p}<0.05$ level. Therefore it is explicit that PEI significantly mediated the relationship between SEI and PDMS. 


\section{a. Mediation by PEI between SEI \& TDMS}

Hypothesis-5 PEI mediates the relationship between SEI- and TDMS.

Computing a

Table 11.

Model Summary.

\begin{tabular}{llllllll}
\hline Model1 & $\mathrm{R}$ & $\mathrm{R}^{2}$ & Adjusted R $^{2}$ & S.E & $\mathrm{F}$ & $\beta$ & $\mathrm{p}$ \\
\hline PEI & $.249^{\mathrm{a}}$ & .062 & .055 & .34280 & 8.344 & & 0.005 \\
& & & & & & 0.249 & 0.005 \\
\hline
\end{tabular}

a. Predictors: (Constant), SEI

a. Dependent Variable: PEI

Regression analysis was used to study the effect of SEI upon PEI. From the results it was evident that SEI shows $6.2 \%$ variance upon PEI, the goodness of fit i.e., $F=8.344$ is significant at $p<0.05$ likewise, $\beta=0.249$ explained that $24.9 \%$ change is possible in PEI because of SEI. A hypothesis 05 is there substantiated and accepted.

Table 12.

Model Summary.

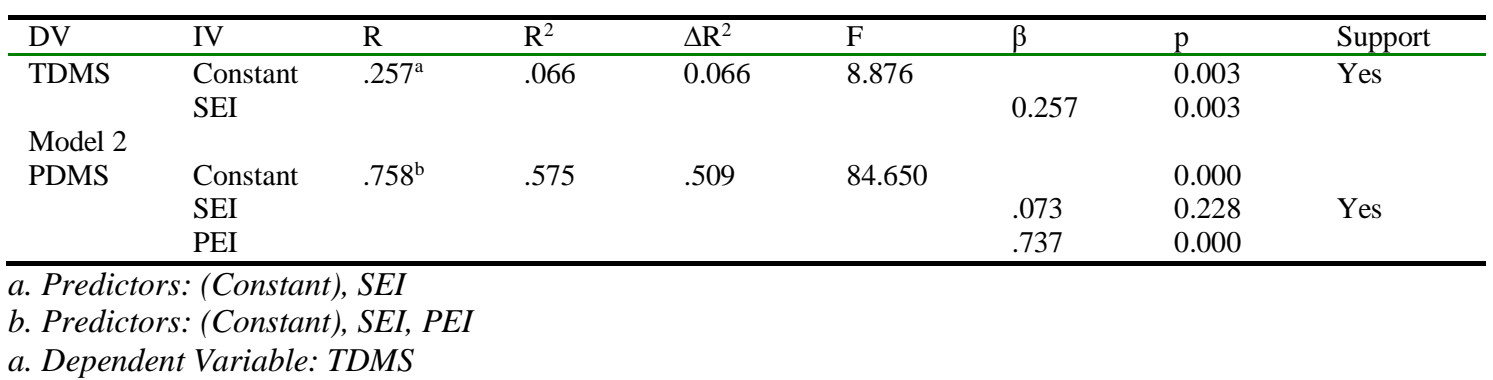

Mediation analysis was run in SPSS. Table 12 illustrates the result for hierarchical multiple regressions. The first model shows $\mathrm{R} 2=0.066$, which means that SEI explained a $6.6 \%$ variance on TDMS. While $\mathrm{F}$ value 8.876 is significant at the $\mathrm{p}<0.05$ level explains the goodness of fit of the model. Moreover, a beta value of 0.257 means one percent change in SEI could bring a $25.7 \%$ possible change in TDMS. In the second model, the mediator PEI was added as per theoretical order/importance, $\mathrm{R} 2=0.575,57.5 \%$ variance is explained by PEI and SEI on TDMS together, in addition, $\mathrm{F}=84.65$ is significant at $\mathrm{p}<0.05$ but value for $\mathrm{SEI}=0.073 \mathrm{p}>0.05$ and PEI beta value is 0.737 at $p<0.05$, This points that $73.7 \%$ change is possible in TDMS due to PEI, and there is no significant role of SEI on TDMS thus PEI plays a significant role as a full mediator between SEI and TDMS, thus a hypothesis 05 is accepted.

\section{Tests of Significance}

This section presents the results of tests of significance for group men difference to quantity the existence and power of group mean i.e., Sector, Gender, Designation, and Experience.

\section{a. Sector}

Table 13.

t-test (Sector: Health/Education)

\begin{tabular}{llllllll}
\hline & Health /Education & $\mathrm{n}$ & Mean & SD & SE Mean & $\mathrm{t}$ & Sig (2-tailed) \\
\hline \multirow{2}{*}{ PEI } & Health/ & 25 & 5.01 & .348 & .071 & 3.171 & .003 \\
& Education & 103 & 4.77 & .339 & .033 & 3.128 & .005 \\
\multirow{2}{*}{ SEI } & Health/ & 25 & 4.17 & .522 & .106 & -1.273 & .173 \\
& Education & 103 & 4.29 & .374 & .036 & -1.129 & .273 \\
\multirow{2}{*}{ TDMS } & Health/ & 25 & 4.91 & .357 & .072 & 5.752 & .000 \\
& Education & 103 & 4.50 & .295 & .028 & 5.198 & .000 \\
\multirow{2}{*}{ PDMS } & Health/ & 25 & 4.91 & .404 & .082 & 1.525 & .134 \\
& Education & 103 & 4.78 & .379 & .037 & 1.554 & .145 \\
\hline
\end{tabular}




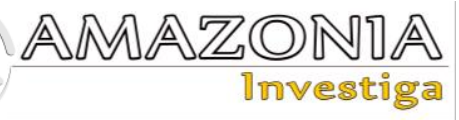

Hypothesis 07 was related to the mean differences based on the 'sector' of the sample respondents. Results bring into fore that the health group is scoring higher than the education sector. The hypothesis has been accepted as true on two constructs i.e., PEI, and TDMS out of the four constructs therefore, the H7 is partially substantiated.

\section{b. Gender}

Table 14.

t-test (Gender)

\begin{tabular}{llllllll}
\hline & Gender & $\mathrm{n}$ & Mean & SD & SE Mean & $\mathrm{t}$ & Sig (2-tailed) \\
\hline \multirow{2}{*}{ PEI } & Male & 78 & 4.93 & .342 & .0399 & 5.045 & .000 \\
& Female & 50 & 4.63 & .291 & .0418 & 5.212 & .000 \\
\multirow{2}{*}{ SEI } & Male & 78 & 4.20 & .357 & .0427 & -2.432 & .016 \\
& Female & 50 & 4.37 & .456 & .0648 & -2.315 & .022 \\
\multirow{2}{*}{ TDMS } & Male & 78 & 4.72 & .295 & .0346 & 6.547 & .000 \\
& Female & 50 & 4.36 & .306 & .0439 & 6.476 & .000 \\
\multirow{2}{*}{ PDMS } & Male & 78 & 4.85 & .394 & .0438 & 1.466 & .130 \\
& Female & 50 & 4.74 & .368 & .0527 & 1.526 & .142 \\
\hline
\end{tabular}

Most of the variables accept the SEI, females score is less than the males. The use of t-test discloses that the hypothesis stands true on 4 variables, however, it is true otherwise on one variable of Social EI. The results are insignificant on PDMS. Therefore, it is established that hypothesis 08 is confirmed with effects on 4 out of 5 variables of the study.

\section{b. Designation}

Table 15.

t-test (DSG)

\begin{tabular}{llllllll}
\hline & Designation & $\mathrm{n}$ & Mean & SD & SE Mean & $\mathrm{t}$ & Sig. (2-tailed) \\
\hline \multirow{2}{*}{ Personal EI } & $18-19$ & 86 & 4.79 & .324 & .034 & -1.115 & .272 \\
\multirow{2}{*}{ Social EI } & $20-21$ & 42 & 4.86 & .404 & .063 & -1.031 & .341 \\
\multirow{2}{*}{ Task-oriented DMS } & $18-19$ & 86 & 4.29 & .378 & .040 & .874 & .375 \\
& $20-21$ & 42 & 4.22 & .463 & .072 & .821 & .410 \\
\multirow{2}{*}{ People-oriented DMS } & $18-19$ & 86 & 4.50 & .283 & .030 & -3.645 & .000 \\
& $20-21$ & 42 & 4.73 & .413 & .064 & -3.265 & .002 \\
& $18-19$ & 86 & 4.81 & .379 & .040 & .031 & .965 \\
& $20-21$ & 42 & 4.80 & .405 & .063 & .037 & .913 \\
\hline
\end{tabular}

The senior officers scored higher than juniors for all constructs except on SEI. However, the score of the t-test discloses that the difference is significant only on TDMS. Similarly, p-values on the rest of the four variables are greater than the threshold value, therefore hypothesis 09 is partially substantiated.

\section{c. Experience}

Table 16.

t-test (Experience)

\begin{tabular}{llllllll}
\hline & Experience & $\mathrm{n}$ & Mean & SD & SE Mean & $\mathrm{t}$ & Sig. (2-tailed) \\
\hline \multirow{2}{*}{ Personal EI } & $>=5$ & 73 & 4.92 & .336 & .039 & 4.212 & .000 \\
& $<5$ & 55 & 4.67 & .323 & .044 & 4.140 & .000 \\
\multirow{2}{*}{ Social EI } & $>=5$ & 73 & 4.33 & .420 & .048 & 2.156 & .034 \\
& $<5$ & 55 & 4.18 & .373 & .050 & 2.177 & .031 \\
\multirow{2}{*}{ Task-oriented DMS } & $>=5$ & 73 & 4.68 & .331 & .038 & 4.384 & .000 \\
& $<5$ & 55 & 4.43 & .311 & .042 & 4.401 & .000 \\
\multirow{2}{*}{ People-oriented DMS } & $>=5$ & 73 & 4.90 & .363 & .042 & 3.257 & .001 \\
& $<5$ & 55 & 4.68 & .382 & .052 & 3.302 & .001 \\
\hline
\end{tabular}


The respondents with greater than $>=5$ years' experience scored higher than the less experienced colleagues, Experience stands significant for all six variables with p-values in an acceptable range. It implies that experience is the most significant variable resulting in the group mean differences among all the respondents and on SEI, PEI, PDMS, TDMS, \& DMS. Thus hypothesis 10 is substantiated and accepted.

Emotion is the subject of research in the fields of psychology, behavioral sciences, sociology, and administration. This study discloses EI plays an instrumental role in determining decision-making. Both Personal EI and Social EI are powerful factors that influence the EI and affect the outcome of the decisionmaking process. This study found personal EI role of managers is more critical than social EI health and education sectors. The impact of personal EI is determined by the correlation, regression, and mediation results that significantly demonstrate the stronger role of personal EI on the decision-making styles. Since emotion influences all kinds of behaviors, therefore, it defines their views throughout their life span, from the moment they are born until they die. It is believed that emotive supremacies of the decision-making personnel affect all decisions. According to Goleman (1998), genuine emotions include passion, anger, distress, grief, and pleasure, wonder, disgust, and humiliation. EI affects the decision-makers social as well as organizational life, its impacts are profound and grave; yet, one cannot accurately determine its extent of limits and magnitude of the impact, therefore remains as a research subject that needs to be explored in detail by the future studies (Hacioglua \&Yarbayb, 2014). Under the stressful environment, decision-making needs more EI to effectively coop with work settings and work requirements. Studies have examined EI and intellectual intelligence, emotion groups, EI abilities, and variation between with regards to genders and EI dimensions. As a consequence, significant developments have been witnessed in the fields of management and administration. Researchers found that effect of emotional power on human life is quite powerful than the intellectual intelligence. This study identified that EI is the instrumental factor that leaders must have to possess. The results on PEI and PDMS are higher than the rest of the variables. The respondents have preferred PDMS and demonstrated greater scores for PEI in contrast to SEI. Task-oriented decision-making style seemed less significant than the people-oriented decision-making style, which confirms that now organizations are focusing on human side. They considers human values and emotions as critical success factors. Unquestionably, today all organizations including health and education render services, therefore, the emotional competence of managers is imperative to manage and control the emotions of their fellows and subordinates for the successful conduct of maximizing the output.

\section{Conclusion}

It is well reported that personal intelligence and social-emotional intelligence significantly influence the development of decision-making style. In this study majority of the hypotheses stands verified as true. The results confirm the dominance of PEI as compared to SEI. The relationship between predictors and criterion variables is consistent with the literature identified in the theoretical framework with small chnages of effect and strength. The scores on PEI are greater than the SEI. This explains that respondents have a greater understanding of PEI. Where their capacity to demonstrate command over SEI is found poor with a nominal role. Remarkably, both personal and social EI are predicting variation in decision-making styles. The role of Personal EI is more prominent than Social EI. It seems that since modern organizations are knowledge workplaces where motivation plays a key role in bringing greater performances. This study finds that PEI is very critical in the case of SEI-PDMS however, there is partial mediation was recorded for PEI in the relationship between SEI-TDMS. Likewise, the people-oriented decision-making style was found to be more popular than the task-oriented style. Social EI is least reordered least association PDMS and TDMS. The literature suggests that personal EI determines the strength and influence of social EI, and our results were consistent with previous studies. The study also reported the significance of the demographics. The experience stands on the top which influenced the responses for all five variables. Similarly, gender also emerged as the second critical variable in affecting the respondents. Sector and designation also play an instrumental role by changing 3, 2, and 1 research variables respectively. Overall, emotional intelligence appeared as a critical success and failure factor in the study. Both people and task-oriented decision-making styles need a level of competence in all dimensions of EI including self-awareness, self-regulation, and motivation (PEI); and empathy and social skills (SEI). In task-oriented decision-making, the role of EI is less important. However, EI affects decision-making because it influences the behavior of the decisionmakers irrespective of the style they adopted for making decisions. The study also concludes that training on emotional intelligence needs to be given priority, thus, managers shall be well-versed with different dimensions of emotions, emotional control, emotion management, and emotional issues both at personal and social levels of interaction with the subordinates, particularly, with the co-workers. 


\section{Implications for the Management and Workforce}

The decision-makers and employees can benefit from the findings of this study using it as a guide to define their future policies in respect to workforce behavior. They can add emotional content to employee training programs for understanding the role of emotions and their management in performing their duties by taking into account both scientific and human requirements in the work setting. The human resource managers might record the measures and emotional competencies i.e., emotional intelligence might be added to an organizational research program with a notion to record the change in the emotional management in the workforce. They can devise the employee's training and coaching programs, for example, a 3-D view of emotional intelligence that includes standard emotional management, measurement of the existing emotional management by managers inter alia implementation as contents of continuous training of employees in emotional management.

\section{Bibliographic references}

Attride-Stirling, J. (2001). Thematic networks: an analytic tool for qualitative research. Qualitative Research, 1(3), 385-405.

Babbie, E. (1993). The practice of social research. 7th ed. Wordsworth Publishing Co.

Baczynska, A. (2015). Analytical, practical, and emotional intelligence and line manager competencies. Management and Business Administration, 23(4), 34-54.

Bar-On, R. (2000). Emotional and social intelligence: Insights from the emotional quotient inventory (EQI), in R. Bar-On \& J. D. Parker (eds.), The Handbook of Emotional Intelligence. San Francisco: JosseyBass.

Bar-On, R. (2006). The Bar-On model of emotional-social intelligence. Psicothema, 18(suppl.), 13-25.

Baron, R. M., \& Kenny, D. A. (1986). The moderator-mediator variable distinction in social psychological research: Conceptual, strategic, and statistical considerations. Journal of personality and social psychology, 51(6), 1173-1182.

Bavolar, J. \& Orosova, O. (2015). Decision-making styles and their associations with decision-making competencies and mental health. Judgment and Decision Making, 10(1), 115-122.

Cadman, C., \& Brewer, J. (2001). Emotional intelligence: A vital prerequisite for recruitment in nursing. Journal of Nursing Management, 9, 321-4.

Del Missier, F., Mäntylä, T., \& Bruine de Bruin, W. (2010). Executive functions in decision making: An individual differences approach. Thinking and Reasoning, 16, 69-97.

Gardner, H. (1983). Frames of Mind: The Theory of Multiple Intelligences. New York: Basic Books.

Gardner, K.J. \& Qualter, P. (2010). Concurrent and incremental validity of three trait emotional intelligence measures. Australian Journal of Psychology, 62(1), 5-13.

Gatseliuk, V., Strelbitska, L., Herasymchuk, O., Pavlyshyn, A., \& Khrystiuk, V. (2021). The influence of religion on the norms of criminal law and process: an international comparative study. Amazonia Investiga, 10(42), 226-235. https://amazoniainvestiga.info/index.php/amazonia/article/view/1672

Glasser, B. G., \& Strauss, A. L. (1967). The discovery of grounded theory: Strategies for qualitative research. Chicago: Aldine.

Goleman, D. (1998). Emotional intelligence. New York: Bantam. Available at: https://books.google.com.sa/books/about/Working_with_Emotional_Intelligence.html?id=ZNbsngEA CAAJ\&redir_esc $=\mathrm{y}$

Goode, W.J. \& P.K. Hatt (1952). Methods in social research. McGraw-Hill.

Hacioglua, B. \&Yarbayb, P. S. (2014). A theoretical assessment on emotional intelligence as a competitive managerial skill. International Journal of Research in Business \& Social Science, 3(1).

Holt, S. (2007). Emotional intelligence and academic achievement in higher education. Stanford: Stanford University Press.

Kang, F. L. (2015). Contribution of Emotional Intelligence towards Graduate Students' Critical Thinking Disposition. International Journal of Education \& Literacy Studies, 3(4).

Luthans, F., \& Youssef, C.M. (2007). Emerging positive organizational behavior. Journal of Management, 33, 321-349.

Luthans, F., \& Youssef-Morgan (2017). Psychological capital: An evidence-based positive approach. Annual Review of Organizational Psychology and Organizational Behavior, 4, 17.1-17.28.

Luthans, F., Avey, J., Avolio, B., \& Peterson, S. (2010). The development and resulting performance impact of positive psychological capital. Human Resource Development Quarterly, 21, 41-67.

Mayer, J.D., \& Salovey, P. (1997). What is emotional intelligence? In P. Salovey, \& D. Sluyter, Emotional development and emotional intelligence: educational implications. New York: Basic Books. 
Mayer, J.D., Roberts, R. D., \& Barsade, S. (2008a). Human abilities: Emotional intelligence. Annual Review of Psychology, 59, 507-536.

Mayer, J.D., Salovey, P. \& Caruso, D.R (2008b) Emotional intelligence: New ability or eclectic traits? American Psychologist, 63(6), 503-517.

Mullakanda, P.S. \& Dissanayake, K. (2015). Strategies for maintaining emotional stability: The case of nurses in the private health care industry. Management Science Letters, 5, 1097-1110.

Rahim, S. H., \& Malik, M. I. (2010). Emotional intelligence \& organizational performance: A case study of the banking sector in Pakistan. International Journal of Business \& Management, 5(10), 191.

Rahmana, S., Uddina, A. \& Rahman, M. (2016). Role of emotional intelligence in managerial effectiveness: An empirical study. Management Science Letters, 237-250.

Ritchie, J. and Spencer, L. (1994). Qualitative Data Analysis for Applied Policy Research. In: Bryman, A. and Burgess, R., Eds., Anal. Qual. London: Data, Routledge, 173-194.

Rowe \& Boulgarides (1983). Decision styles: A perspective. Leadership \& Organization Development Journal, 4(4), 3-9.

Salovey, P., \& Mayer, J.D. (1990). Emotional intelligence. Imagination, Cognition and Personality, 9, 185-211.

Sarkhosh, M. \& Rezaee, A.A. (2014). How does university teachers' emotional intelligence relate to their self-efficacy beliefs? Porta Linguarum, 21, 85-100.

Schutte, M.S., Malouff, J.M., Hall, L.E., Haggerty, D.J., Cooper, J.T., Golden, C.J., \& Dornheim, L. (1998). Development and validation of a measure of emotional intelligence. Personality and Individual Differences, 25, 167-177.

Sekaran, U. (1999). Research methods for business: A skill-building approach. 3rd Ed. John Wiley \& Sons. Available at: https://www.wiley.com/enus/Research+Methods+For+Business $\% 3 \mathrm{~A}+\mathrm{A}+$ Skill+Building+Approach\%2C+7th+Edition-p9781119266846

Sims, H.P., Faraj, S., \& Yun, S. (2009). When should a leader be directive or empowering? How to develop your own situational theory of leadership. Business Horizons, 52, 149-158.

Svetlana, H. (2007). Emotional Intelligence and Academic Achievement in Higher Education. Pepperdine University.

Toulmin, S. (1958). The uses of argument. Cambridge University Press, Cambridge.

Toulmin, S. (2003). The Uses of Argument, 2nd Ed.) Cambridge: Cambridge University Press. Doi: 10.1017/CBO9780511840005

Zimmerman, B. J., \& Schunk, D. H. (2011). Self-regulated learning and performance. In B. J. Zimmerman and D. H. Schunk (Eds.), Handbook of self-regulation of learning and performance (pp. 1-12). New York: Routledge. 